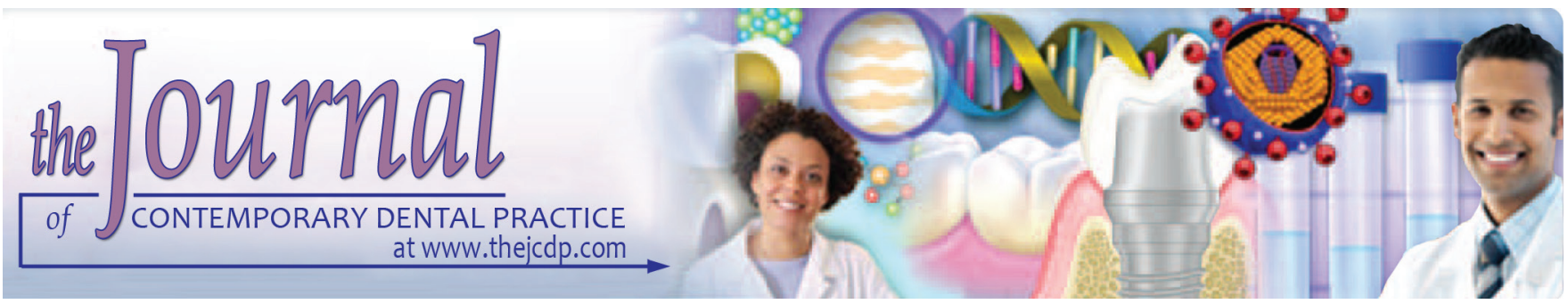

\title{
Evaluation of Relationship between Exposure Parameters and Maxillofacial Bone Quality with Salivary Glands Absorbed Dose in Cone Beam Computed Tomography Imaging
}

\author{
${ }^{1}$ Mojdeh Mehdizadeh, ${ }^{2}$ Shervin Bagherieh
}

\section{ABSTRACT}

Aim: The purpose of this study was to evaluate the protective effect of jaw bone on the dose of salivary glands and its relationship with radiation conditions.

Materials and methods: In this cross-sectional study, seven dried human skulls were used. In each mandible, six dosimeters were placed in six salivary gland regions numbered in visible light absorbent envelopes. Cone beam computed tomography (CBCT) images were taken from each mandible with a constant $\mathrm{kV}$ of 90 and $\mathrm{mA}$ varied from 6,8 , and 10 . The absorbed dose was calculated using SOLAR 2A. The bone quality of each of the six areas was obtained using densitometry tool in On Demand software. Finally, the results were analyzed using Statistical Package for the Social Sciences (SPSS) software version 23 with covariance and Tukey tests $(\alpha=0.05)$.

Results: The results of covariance analysis and Tukey test indicated that the sublingual salivary gland had the highest absorption dose. Meanwhile, the results of the analysis showed that the absorption rate of the glands increased by increasing the radiation conditions from 6 to 8 and increasing from 8 to $10 \mathrm{~mA}(p<0.001)$. The results of Pearson analysis showed an inverse relationship between absorbed dose and bone quality $(r=-0.327)(p<0.001)$.

Conclusion: The results of this study showed that the absorption rate of salivary glands will increase with increasing radiation conditions, while increasing the quality of mandibular bone, the absorption dose will decrease.

\footnotetext{
${ }^{1}$ Department of Oral and Maxillofacial Radiology, School of Dentistry, Isfahan University of Medical Sciences, Isfahan Islamic Republic of Iran

${ }^{2}$ Department of Endodontics, School of Dentistry, Isfahan University of Medical Sciences, Isfahan, Islamic Republic of Iran

Corresponding Author: Shervin Bagherieh, Department of Endodontics, School of Dentistry, Isfahan University of Medical Sciences, Isfahan, Islamic Republic of Iran, Phone: +989132881338, e-mail: shervinbgh@yahoo.com
}

Clinical significance: The clinical significance is to reduce patient's absorbed dose in order to decrease the risk of mutation and cancer formation.

Keywords: Bone quality, Cone beam computed tomography, Dosimetry, Salivary glands.

How to cite this article: Mehdizadeh M, Bagherieh S. Evaluation of Relationship between Exposure Parameters and Maxillofacial Bone Quality with Salivary Glands Absorbed Dose in Cone Beam Computed Tomography Imaging. J Contemp Dent Pract 2018;19(5):568-573.

Source of support: Nil

Conflict of interest: None

\section{INTRODUCTION}

Since using X-ray in the oral cavity by Dr Valkhov in 1986 for the first time, oral diagnostic imaging has undergone widespread development. Generally, oral imaging is divided into (1) intraoral and extraoral, (2) analog and digital, (3) ionizing and nonionizing, and (4) twodimensional (2D) and three-dimensional (3D) imaging. ${ }^{1}$

The CВCT has been designed and produced since late 1990s exclusively for imaging maxillofacial zone. ${ }^{2}$

Among the advantages of CBCT 3D images, compared with the 2D images, we can refer to the ease of estimating the sizes and ratios, providing general view about the study area, observing careful details in less than $\mathrm{mm}$ range, and accurate study of the relationships between anatomic elements. ${ }^{3,4}$ Although medical CT scan images are accessible in 3D form, regarding the significant reduction in the dose received by patient and increasing the quality of images in the head and face zone and also reducing noise of views, it is better to use $\mathrm{CBCT}$. 5,6

Today, CBCT plays an important role in the dentistry treatments; these images are used to diagnose the suitable 
place for embedding implant, maxillofacial surgeries, diagnosing temporomandibular joint disorders, endodontic, orthodontic, and periodontics treatments. ${ }^{7,8}$

The dose received by patient during CBCT depends on different factors including continuous or pulsed X-ray radiation, tube rotation angle, ray filtration, voxel size, and radiation conditions. ${ }^{9}$

Despite the low dose received by the patient during dental radiography, there are always concerns about the carcinogenicity caused by X-ray in children. ${ }^{10,11}$

The null hypothesis of this study is that there is no relationship of absorbed doses of $X$-ray by salivary glands and quality of the bone.

This research aims to study the relationship of absorbed doses of X-ray and quality of mandible bone.

\section{MATERIALS AND METHODS}

Seven dried human skulls were used in this study. Six thermoluminescent dosimeters (TLDs) were placed for each skull (Fig. 1), one pair in the parotid gland lobe zone, one pair in submandibular gland zone, and one pair in sublingual zone. The TLDs (Harshaw Chemical Co., Solon, Ohio, USA) were placed in numbered plastic covers and installed on the given area.

The CBCT test time (Soredex-Tuusula-Finland) was 12.6 seconds. $\mathrm{kVp}$ was constant in $90 \mathrm{kVp}$, while $\mathrm{mA}$ changed in the intervals 6,8 , and 10 . In order to measure the absorbed dose, 42 TLDs were used. This dosimeter can be cleaned by reading apparatus (NE Technology, United Kingdom) or furnace. A TLD reading meter was used to calculate the dose. The output of the apparatus is correct counting of light photons releases by heating. The TLDs were calibrated in both individual and group steps.

For individual calibration, dosimeters were under 20 mGy radiation of Cobalt 60 gamma ray and then read

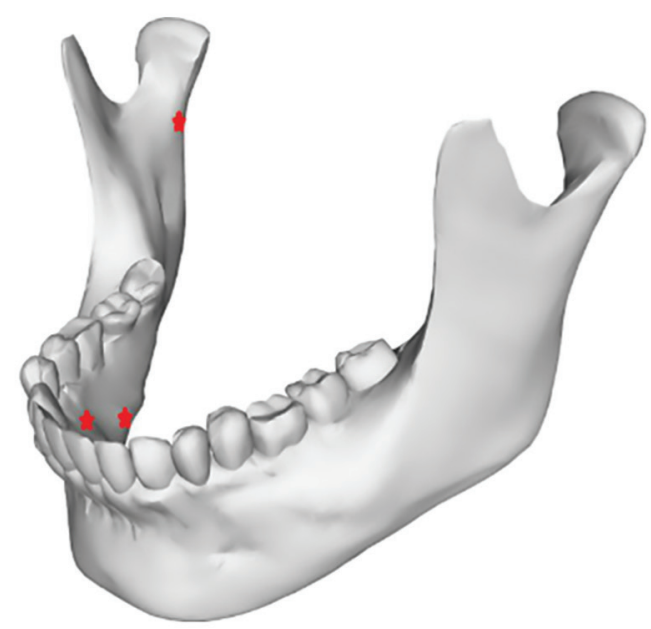

Fig. 1: Positon of TLDs in human dried skull
Table 1: Dosimeter radiation quantities for determining batch calibration factor

\begin{tabular}{llll}
\hline Subgroup & $\begin{array}{l}\text { Dosimeters } \\
\text { label number }\end{array}$ & $\begin{array}{l}\text { Duration of } \\
\text { irradiation }(\mathrm{min})\end{array}$ & $\begin{array}{l}\text { Dose of } \\
\text { irradiation }(m G y)\end{array}$ \\
\hline 1 & $1-6$ & 0.49 & 5 \\
2 & $7-12$ & 0.99 & 10 \\
3 & $13-18$ & 1.49 & 15 \\
4 & $19-24$ & 1.99 & 20 \\
5 & $25-30$ & 2.49 & 25 \\
6 & $31-36$ & 2.99 & 30 \\
7 & $37-42$ & 0 & 0 \\
\hline
\end{tabular}

by the meter. Individual calibration factor can be calculated by the following equation:

$$
\text { Individual calibration factor }=\frac{\text { mean group response }}{\text { individual response }}
$$

For group calibration, dosimeters were divided into seven groups of six dosimeters and each group received a certain dose of Cobalt 60 gamma ray according to Table 1 .

A group without radiation was studied in order to determine the basic dose.

After reading the groups, dose-counting curves were drawn. The group calibration factor was obtained by the following equation:

$$
\text { Group calibration factor }=\frac{1}{\text { gradient of curve }}
$$

Solar 2A apparatus made by NE Technology was used for reading TLDs. The output of the apparatus in the form of revised counting was as per the following equation:

$$
\begin{aligned}
\text { Revised counting }= & (\text { raw counting-dark current counting }) \times \\
& \text { internal light factor }
\end{aligned}
$$

In this equation, the dark current counting is obtained in the light-enhancing tube and depends on the voltage and tube structure; because it occurs during nonradiation, it should be deduced from the total counting. The internal light factor is determined by the manufacturer.

Finally, the following equation was used to convert the counting to dose:

Calculated dose: (group calibration factor $\times$ revised counting)

- (basic ray $\times$ individual calibration factor)

The CBCT images were studied by using On Demand 3D software 9 Cyber Med Inc., Korea.

In order to calculate the bone quality in panoramic view with thickness 20 , each half-jaw was divided into 24 Hash line.

The bone quality of the studied zones was calculated using densitometry tool in square-form zones with dimensions $0.2 \times 0.2$ (inch) based on Hounsfield number (Fig. 2).

The SPSS 23 software was used for data analysis. The relationship between changing radiation conditions, mean received dose, and mean bone quality was studied by using bivariate covariance analysis. Bivariate variance analysis and Tukey test were used to compare the amount 


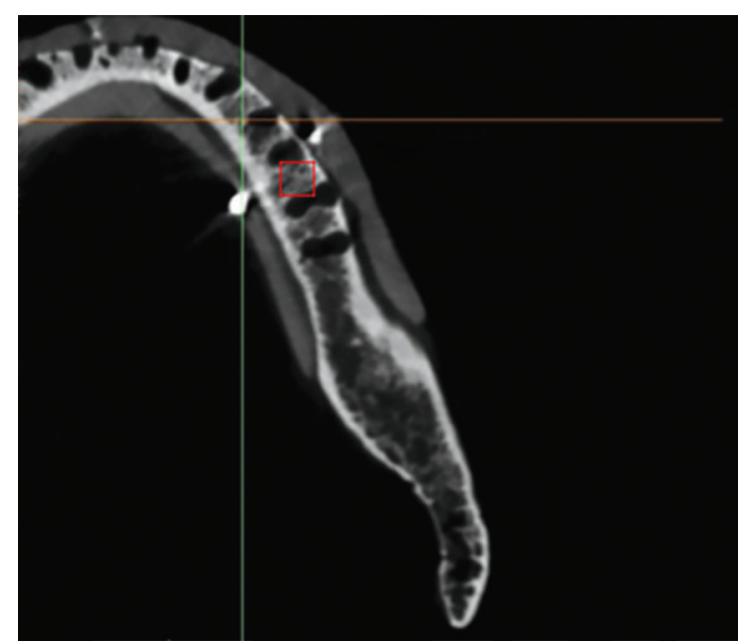

Fig. 2: Cone beam computed tomography image while detecting bone quality

of dose received by different salivary glands and the relationship between increasing radiation condition and the amount of received dose as well. Pearson statistical test was used to study the relationship between received doses in tissues and bone quality in the radiation zone $(\alpha=0.05)$.

\section{RESULTS}

Mean and standard deviation of received doses by tissues are presented in Table 2 and Graphs 1 and 2, based on the radiation conditions and place.
In order to compare the received doses in different radiation conditions and places and by considering the bone quality variance, two-way covariance analysis was done which showed that there is a significant relationship between radiation conditions ( $p$-value $<0.001$ ). There was also a significant difference among radiation points $(p$-value $=0.007)$. The interaction between radiation condition and place is not significant ( $p$-value $=0.986$ ).

Tukey posttest showed that the received dose in the sublingual glands is significantly higher than in the submandibular and parotid glands (Table 3).

Tukey posttest also showed that by increasing radiation from 6 to $8 \mathrm{~mA}$ (p-value $<0.001$ ) and from 8 to $10 \mathrm{~mA}$ ( $p$-value $<0.001$ ), the dose received by tissues increases significantly.

The results of Pearson statistical test showed that there is a reverse correlation between the received doses by tissues and the bone quality of the radiated zone $(\mathrm{r}=0.327)(\mathrm{p}$-value $<0.001)$.

Graph 3 shows the relationship between the received doses by organs with the bone quality of radiated zone.

Regression analysis was used to determine the relationship between radiation conditions $(\mathrm{mA})$, doses received by glands, and bone quality of radiated zone that the following equation was obtained ( $p$-value $<0.001$ ):

$$
\text { Dose }=0.01 R-0.0004 \mathrm{D}-0.331
$$

Table 2: Mean and standard deviation (SD) of received doses by tissues

\begin{tabular}{|c|c|c|c|c|c|c|c|c|c|c|c|c|c|}
\hline \multirow{3}{*}{\multicolumn{2}{|c|}{ Exposure (mA) }} & \multicolumn{6}{|c|}{ Left } & \multicolumn{6}{|c|}{ Right } \\
\hline & & \multicolumn{2}{|c|}{ Left parotid } & \multicolumn{2}{|c|}{ submandibular } & \multicolumn{2}{|c|}{ Left sublingual } & \multicolumn{2}{|c|}{ Right sublingual } & \multicolumn{2}{|c|}{ submandibular } & \multicolumn{2}{|c|}{ Right parotid } \\
\hline & & $\begin{array}{l}\text { Dose } \\
\text { (mG) }\end{array}$ & $\begin{array}{l}\text { Density } \\
(H U)\end{array}$ & $\begin{array}{l}\text { Dose } \\
(m G)\end{array}$ & $\begin{array}{l}\text { Density } \\
(H U)\end{array}$ & $\begin{array}{l}\text { Dose } \\
(m G)\end{array}$ & $\begin{array}{l}\text { Density } \\
(H U)\end{array}$ & $\begin{array}{l}\text { Dose } \\
(m G)\end{array}$ & $\begin{array}{l}\text { Density } \\
(H U)\end{array}$ & $\begin{array}{l}\text { Dose } \\
(m G)\end{array}$ & $\begin{array}{l}\text { Density } \\
(H U)\end{array}$ & $\begin{array}{l}\text { Dose } \\
\text { (mG) }\end{array}$ & $\begin{array}{l}\text { Density } \\
(H U)\end{array}$ \\
\hline \multirow[t]{2}{*}{$6 \mathrm{~mA}$} & Mean & 2.8 & 380 & 3 & 379 & 5 & 174 & 4.9 & 156 & 3.6 & 346 & 3.5 & 319 \\
\hline & SD & 1.3 & & 1.8 & & 1 & & 1 & & 1.2 & & 1.1 & \\
\hline \multirow[t]{2}{*}{$8 \mathrm{~mA}$} & Mean & 5.5 & & 5.9 & & 6.9 & & 7.3 & & 6.2 & & 6.2 & \\
\hline & SD & 0.8 & & 1.4 & & 1.1 & & 0.9 & & 1.3 & & 1.1 & \\
\hline \multirow[t]{2}{*}{$10 \mathrm{~mA}$} & Mean & 8.4 & & 9 & & 10.4 & & 1.02 & & 9.2 & & 9 & \\
\hline & SD & 1.1 & & 1.2 & & 1.2 & & 0.8 & & 0.7 & & 1.2 & \\
\hline
\end{tabular}

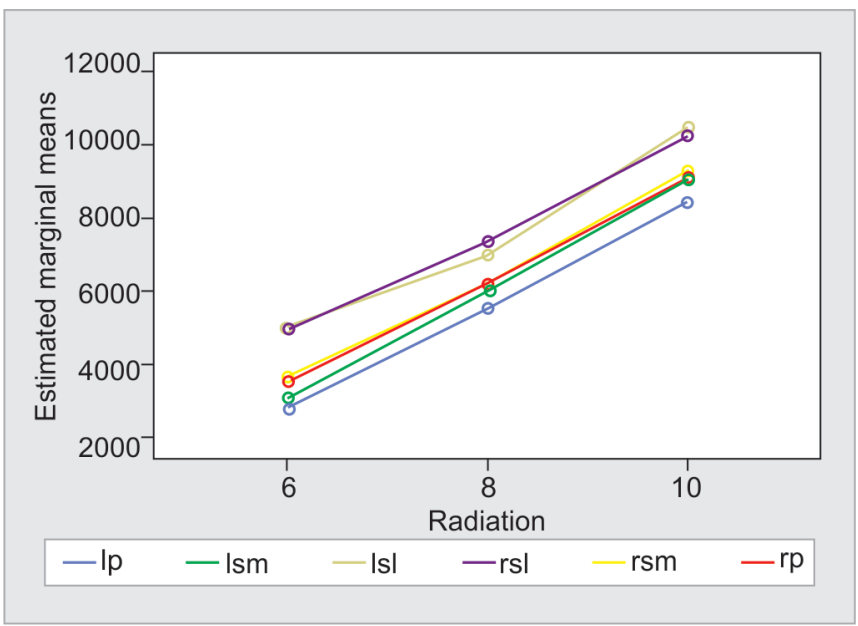

Graph 1: Relationship between organ's mean absorbed dose and bone density

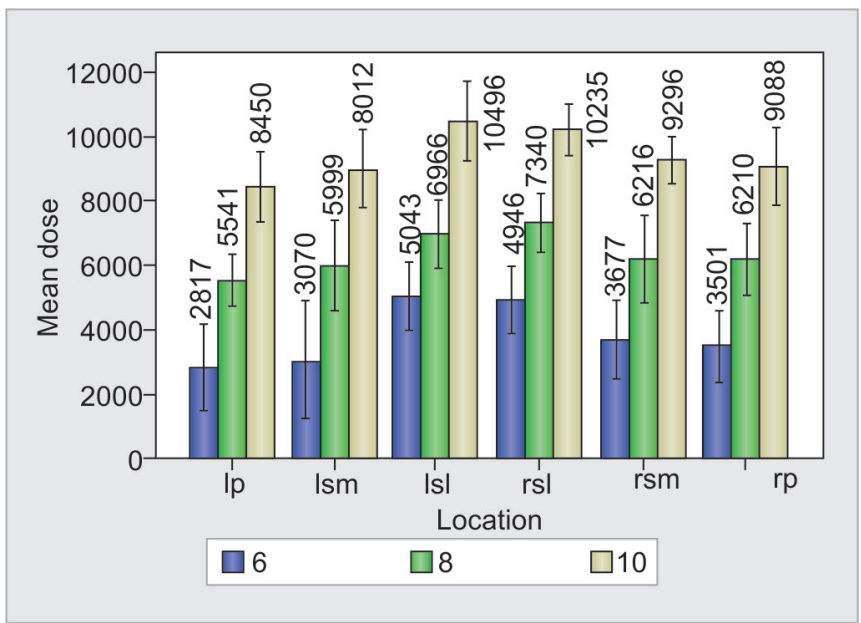

Graph 2: Comparison of organ's mean absorbed dose under different exposure parameters 
Table 3: Tukey test results

\begin{tabular}{lll}
\hline Region & $\begin{array}{l}\text { Mean dose in first } \\
\text { subgroup }(m G)\end{array}$ & $\begin{array}{l}\text { Mean dose in second } \\
\text { subgroup }(m G)\end{array}$ \\
\hline Left parotid & 5.6 & \\
Left submandibular & 6 & \\
Right parotid & 6.2 & \\
$\begin{array}{l}\text { Right submandibular } \\
\text { Left sublingual }\end{array}$ & 6.3 & 7.5 \\
Right sublingual & & 7.5 \\
p-value & 0.25 & 1 \\
\hline
\end{tabular}

where $\mathrm{R}$ is the radiation in $\mathrm{mA}$ and $\mathrm{D}$ is the bone quality in $\mathrm{HU}$

\section{DISCUSSION}

Results of the present study indicated that by increasing the radiation current from 6 to 8 and 8 to $10 \mathrm{~mA}$, the absorbed doses by salivary glands increased significantly. In other words, in each point with constant bone quality, by increasing the radiation, the amount of absorbed dose increases and in the same radiation condition in points with different bone quality, areas with higher bone quality will receive a lower dose.

Increasing the absorbed dose in different salivary glands from 6 to $8 \mathrm{~mA}$ was more significant than the increase of those from 8 to $10 \mathrm{~mA}$. The highest changes in received doses related to the doses of parotid and submandibular glands. The mean bone density of these two areas was higher relative to other areas. Based on this, it does not seem that an increase in the bone quality creates any protection against increase in the absorbed dose during increase in the radiation conditions.

Among studied salivary glands in this study, sublingual glands have the highest received dose; in addition, the bone density of sublingual glands' area was the lowest amount among the studied area. The least received dose between studied glands related to the left parotid glands which have the highest bone density among the studied points.

The obtained relationship by regression analysis indicates that received doses of tissues have a direct relationship with radiation intensity and an inverse relationship with bone quality.

In this study, the highest and lowest received doses related to sublingual glands and parotid glands respectively. Because CBCT image in this study belonged to mandible bone, there was inconsistency in terms of result with the studies which have used maxilla CBCT images.

The obtained results suggest that in every radiation condition, by increasing the bone quality of radiation point, the received doses by salivary glands decrease and vice versa, while by increasing the radiation, the protective feature of bone density in reducing absorbed doses

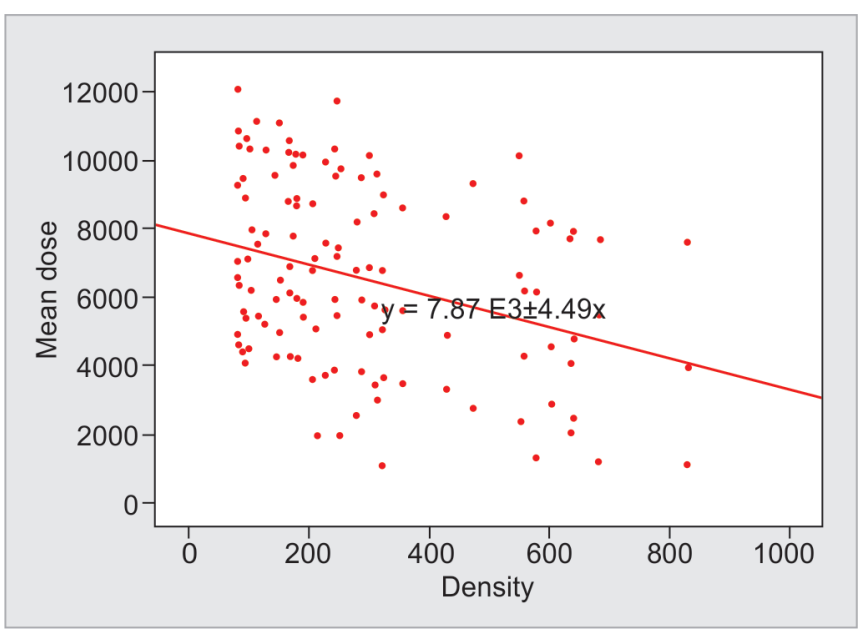

Graph 3: Relationship between organ's absorbed dose and bone density

decreases and the difference between absorbed doses of different point decreases as well.

Various studies have been done to study the bone quality by using CBCT images.

Nomura et $\mathrm{al}^{12}$ stated that using gray scale CBCT images enables the estimation of bone density.

Parsa et $\mathrm{al}^{13}$ concluded in their research that there is a strong correlation between gray scale values in CBCT images and bone density.

Various studies have been done about reducing the received dose by the patient in CBCT imaging.

Sezgin et $\mathrm{al}^{14}$ admitted that by reducing the imaging field of view, the amount of received doses by salivary glands reduces significantly.

Qu et $\mathrm{al}^{15}$ studied the effect of tube current on the amount of absorbed dose. Their results are consistent with our results that by increasing the imaging current intensity, the amount of absorbed dose by patient increases.

In a research by Palomo et $\mathrm{al}^{16}$ which only studied the amount of absorbed dose by submandibular glands, it was seen that by increasing the current, the amount of absorbed dose increases significantly.

In a research by Ludlow et $\mathrm{al}^{17}$ about preparing CBCT images from the mandible, as in the present study, the highest and lowest received doses related to sublingual and parotid glands respectively. In this study, the relationship between radiation and received dose was not examined.

In a study by Silva et $\mathrm{al}^{18}$ the amount of received dose by parotid glands in radiation with I-CAT and New Tom 9000 systems was higher than the amount received by submandibular glands. In this research, the received doses by sublingual glands were not determined. The obtained doses by Silva were less than the calculated dose in the present study, which is caused by the lack of dosereducing soft tissue on the dried skulls used in this study. 
In another study by Ludlow and Walker, ${ }^{19}$ by reducing the radiation time and rapid imaging, it was seen that the received doses by organs reduced significantly, although the quality of images was significantly low.

Sur et $\mathrm{al}^{20}$ studied the relationship between ray tube current intensity and received doses by organs. Their results, as the results of this study, indicated the increase in received doses by organs with ray current intensity increase. But, in contrast with Ludlow studies, the reduction of image quality was not seen by a reduction in the radiation intensity.

The study of Akyalcin et $\mathrm{al}^{21}$ indicated that by increasing the radiation intensity, the received doses by patient increase significantly, and the quality of the images improves. They suggested that the current intensity should remain low to the point that it does not affect the quality of an image.

In the Morant et $\mathrm{al}^{22}$ study, the highest absorbed dose among maxillofacial organs on a phantom related to the salivary glands, but in this study, the amount of received doses by salivary gland has not been reported separately.

In a Ding et al research, ${ }^{23}$ by changing the radiation condition (voltage) and radiation time, a similar result was obtained in which by increasing the radiation of time and conditions, the exposure of the patient will increase significantly.

Among limitations of this study, we can refer to the impossibility of calculating the effect of soft tissue on the radiation dose because of using dried skull. It is suggested that future studies conduct by using Rando phantom.

\section{CONCLUSION}

Results of the present study indicated the increase of the received doses by organs with reducing the quality of bone and increasing radiation intensity. Therefore, it seems that in order to select suitable imaging conditions in people with weak bone quality, the radiation remains low in order to reduce the received doses by glands without affecting the quality of image.

The limitation of this study lies in not calculating the thickness of soft tissues because of using dried skull; therefore, it is suggested that in the future, studies be conducted by using phantom with soft tissue to calculate the effect of nonbone tissue.

\section{REFERENCES}

1. Shah N, Bansal N, Logani A. Recent advances in imaging technologies in dentistry. World J Radiol 2014 Oct;6(10):794-807.

2. Suomalainen A, Pakbaznejad Esmaeili E, Robinson S. Dentomaxillofacial imaging with panoramic views and cone beam CT. Insights Imaging 2015 Feb;6(1):1-16.

3. Chidiac JJ, Shofer FS, Al-Kutoub a, Laster LL, Ghafari J. Comparison of CT scanograms and cephalometric radiographs in craniofacial imaging. Orthod Craniofac Res 2002 May; 5(2):104-113.

4. Matzen LH, Wenzel A. Efficacy of CBCT for assessment of impacted mandibular third molars: a review-based on hierarchical model of evidence. Dentomaxillofac Radiol 2015;44(1):20140189.

5. Demeslay J, Vergez S, Serrano E, Chaynes P, Cantet P, Chaput B, de Bonnecaze G. Morphological concordance between CBCT and MDCT: a paranasal sinus-imaging anatomical study. Surg Radiol Anat 2016 Jan;38(1):71-78.

6. De Cock J, Zanca F, Canning J, Pauwels R, Hermans R. A comparative study for image quality and radiation dose of a cone beam computed tomography scanner and a multislice computed tomography scanner for paranasal sinus imaging. Eur Radiol 2015 Jul;25(7):1891-1900.

7. Kapila SD, Nervina JM. CBCT in orthodontics: assessment of treatment outcomes and indication for its use. Dentomaxillofac Radiol 2015;44(1):20140282.

8. Larheim TA, Abrahamsson AK, Kristensen M, Arvidsson LZ. Temporomandibular joint diagnostics using CBCT. Dentomaxillofac Radiol 2015;44(1):20140235.

9. Scarfe WC, Levin MD, Gane D, Farman AG. Use of cone beam computed tomography in endodontics. Int J Dent 2010 Mar;2009:634567.

10. Fontenot JD, Lee AK, Newhauser WD. Risk of secondary malignant neoplasms from proton therapy and intensitymodulated x-ray therapy for early-stage prostate cancer. Int J Radiat Oncol Biol Phys 2009 Jun;74(2):616-622.

11. Yoon M, Ahn SH, Kim J, Shin DH, Park SY, Lee SB, Shin KH, $\mathrm{Cho} \mathrm{KH}$. Radiation-induced cancers from modern radiotherapy techniques: Intensity-modulated radiotherapy versus proton therapy. Int J Radiat Oncol Biol Phys 2010 Aug;77(5):1477-1485.

12. Nomura Y, Watanabe H, Shirotsu K, Honda E, Sumi $Y$, Kurabayshi T. Stability of voxel values from cone-beam computed tomography for dental use in evaluating bone mineral content. Clin Oral Implants Res 2013 May;24(5):543-548.

13. Parsa A, Ibrahim N, Hassan B, van der Stelt P, Wismeijer D. Bone quality evaluation at dental implant site using multislice CT, micro-CT, and cone beam CT. Clin Oral Implants Res 2015 Jan;26(1):e1-e7.

14. Sezgin ÖS, Kayipmaz S, Yasar D, Yilmaz AB, Ozturk MH. Comparative dosimetry of dental cone beam computed tomography, panoramic radiography, and multislice computed tomography. Oral Radiol 2012 Mar;28(1):32-37.

15. Qu XM, Li G, Ludlow JB, Zhang ZY, Ma XC. Effective radiation dose of ProMax 3D cone-beam computerized tomography scanner with different dental protocols. Oral Surg Oral Med Oral Pathol Oral Radiol Endod 2010 Dec;110(6):770-776.

16. Palomo JM, Rao PS, Hans MG. Influence of CBCT exposure conditions on radiation dose. Oral Surg Oral Med Oral Pathol Oral Radiol Endod 2008 Jun;105(6):773-782.

17. Ludlow JB, Davies-Ludlow LE, Brooks SL. Dosimetry of two extraoral direct digital imaging devices: NewTom cone beam CT and Orthophos Plus DS panoramic unit. Dentomaxillofac Radiol 2003 Jul;32(4):229-234.

18. Silva MA, Wolf U, Heinicke F, Bumann A, Visser H, Hirsch E. Cone-beam computed tomography for routine orthodontic treatment planning: a radiation dose evaluation. Am J Orthod Dentofacial Orthop 2008 May;133(5):640.e1-640.e5.

19. Ludlow JB, Walker C. Assessment of phantom dosimetry and image quality of i-CAT FLX cone-beam computed tomography. Am J Orthod Dentofacial Orthop 2013 Dec;144(6):802-817. 
20. Sur J, Seki K, Koizumi H, Nakajima K, Okano T. Effects of tube current on cone-beam computerized tomography image quality for presurgical implant planning in vitro. Oral Surg Oral Med Oral Pathol Oral Radiol Endod 2010 Sep;110(3):e29-e33.

21. Akyalcin S, English JD, Abramovitch KM, Rong XJ. Measurement of skin dose from cone-beam computed tomography imaging. Head Face Med 2013 Oct;9(1):28.
22. Morant JJ, Salvadó M, Hernández-Girón I, Casanovas R, Ortega R, Calzado A. Dosimetry of a cone beam CT device for oral and maxillofacial radiology using Monte Carlo techniques and ICRP adult reference computational phantoms. Dentomaxillofac Radiol 2014 Mar;42(3):92555893.

23. Ding GX, Munro P, Pawlowski J, Malcolm A, Coffey CW. Reducing radiation exposure to patients from $\mathrm{kV}-\mathrm{CBCT}$ imaging. Radiother Oncol 2010 Dec;97(3):585-592. 